\title{
RECOBRIMENTO DE SEMENTES DE BRÓCOLOS E SALSA COM COBERTURAS E FILMES BIODEGRADÁVEIS ${ }^{(1)}$
}

\author{
PATRÍCIA SAYURI TANADA-PALMU ${ }^{(2)}$; PAULA DE SALLES PENTEADO PROENÇA ${ }^{(2,4)}$; \\ PAULO ESPÍNDOLA TRANI ${ }^{(3)}$; FRANCISCO ANTONIO PASSOS ${ }^{(3)}$; \\ CARLOS RAIMUNDO FERREIRA GROSSO ${ }^{(2)}$
}

\begin{abstract}
RESUMO
O objetivo deste trabalho foi a comparação do desempenho de sementes de brócolos e de salsa cobertas ou aderidas a filmes biodegradáveis de quitosana e gelatina. Inicialmente, determinou-se o número ótimo de camadas de cobertura e a espessura do filme, para não comprometer a germinação das sementes. O desempenho foi avaliado por meio da capacidade de germinação e do vigor, e pelas massas de material fresco e seco de plantas com cerca de 30 dias. Observou-se germinação inferior ao controle nas sementes inseridas às fitas. $\mathrm{O}$ recobrimento de sementes obteve bons resultados em termos de vigor e desenvolvimento das plantas. Pelos resultados indicados, verificou-se que o recobrimento de sementes, com coberturas biodegradáveis, pode ser promissor, devido à melhoria na germinação das sementes recobertas e também no desenvolvimento das plantas quando comparadas às sementes sem tratamento.
\end{abstract}

Palavras-chave: quitosana, sementes de salsa e brócolos, plantas, germinação, vigor.

\section{ABSTRACT \\ COVERING BROCCOLI AND PARSLEY SEEDS WITH BIODEGRADABLE FILMS AND COATINGS}

The objective of this work was to compare the performance of broccoli and parsley seeds coated or adhered to biodegradable films of gelatin and chitosan. Initially, the optimum number of coating layers and the thickness of the film were determined in order not to affect the germination of seeds. The performance was evaluated by germination capacity and vigor, and by fresh and dry weight of plants with 30 days. The seeds inserted into the films of gelatin and chitosan showed lower germination results than the control seeds. The coating of the seeds with gelatin and chitosan coatings of had good results in terms of vigor and development of plants. The results indicated that coating the seeds with biodegradable coatings can be promising due to the improvement of the germination of the coated seeds and the development of the plants when compared to the seeds with not treated.

Key words: chitosan, broccoli and parsley seeds, plants, germination, vigor.

$\left.{ }^{1}\right)$ Recebido para publicação em 4 de junho de 2004 e aceito em 23 de fevereiro de 2005.

$\left(^{2}\right)$ Departamento de Alimentos e Nutrição, Faculdade de Engenharia de Alimentos, UNICAMP, Caixa Postal 6121, 13083-862 Campinas (SP).

$\left(^{3}\right)$ Centro de Análise e Pesquisa Tecnológica de Horticultura, IAC, Caixa Postal 28, 13001-970 Campinas (SP).

$\left({ }^{4}\right)$ Bolsista de Iniciação Científica da FAPESP. 


\section{INTRODUÇÃO}

Recentemente, tem havido grande interesse no desenvolvimento de filmes ou coberturas biodegradáveis, principalmente pelo impacto ambiental provocado pela degradação muito lenta das embalagens convencionais de alimentos. Além disso, há oportunidades para a criação de novos mercados para matérias-primas renováveis, derivadas de produtos agrícolas, na produção de filmes (TANADAPalmu e Grosso, 2002a,b; Park, 1999; Amarante e BANKS, 2001). O filme biodegradável é uma película fina à base de material biológico, que pode agir como uma barreira a elementos externos tais como umidade, óleo e gases e, conseqüentemente, confere maior proteção ao produto revestido, aumentando assim seu armazenamento. Entre as propriedades funcionais dos filmes biodegradáveis podem ainda ser mencionados o transporte de gases $\left(\mathrm{O}_{2}\right.$ e $\left.\mathrm{CO}_{2}\right)$ e de solutos; a retenção de compostos aromáticos e o transporte e a incorporação de aditivos alimentícios, tais como, nutrientes, aromas, pigmentos ou agentes antioxidantes e antimicrobianos.

A utilização da técnica de recobrimento de sementes com uma camada polimérica fina e uniforme de filme, para minimizar a perda dos aditivos aplicados, pode representar boa alternativa para a agricultura (DUAN e BURRIS, 1997). As sementes com esse recobrimento têm, praticamente, forma e tamanho iguais à semente sem cobertura, com ganho mínimo de massa. Aos filmes e, conseqüentemente, às sementes, podem ser incorporados pesticidas, nutrientes, corantes e outros aditivos (BUTLER, 1993).

As coberturas biodegradáveis enriquecidas com nutrientes, além de melhorar a emergência das plântulas, também podem auxiliar no seu crescimento. Os agricultores, porém, têm sido reticentes em adotar novos métodos, que alterem hábitos consagrados de manejo das plantações (SHAYA et al., 1991).

A composição do material de recobrimento das sementes pode influenciar a germinação, inibir o ressecamento das raízes, controlar a infestação por pragas e auxiliar na fertilização do solo nas proximidades da semente. Entre os exemplos de culturas beneficiadas, podem ser citados o algodão e o feijão, com aumento de $20 \%$ a $30 \%$ no índice de germinação (Nussinovitch, 1997). Sementes de arroz, recobertas com filme de alginato de sódio e óxido de cálcio, germinaram melhor e, nas plantas, ocorreu melhor crescimento em relação às sementes não recobertas, atribuindo-se esses resultados à presença de óxido de cálcio e aos compostos antibióticos adicionados à solução filmogênica. Sementes de ervilha foram tratadas contra o apodrecimento da raiz, utilizando-se um filme de alginato, verificando-se, também, aumento no tamanho médio das plantas. Esse estudo comprovou a efetividade do uso de cobertura de sementes no controle de microorganismos (Dandurand e KnUdSen, 1993).

O objetivo do presente trabalho foi avaliar os efeitos da cobertura ou inclusão em fitas biodegradáveis na germinação e no vigor de sementes de brócolos e de salsa.

\section{MATERIAL E MÉTODOS}

Inicialmente, a quitosana (PADETEC-UFC) passou por um processo de desacetilação, sendo dissolvida em solução de hidróxido de sódio (25\%), na proporção de 1:5 (p/v) em temperatura ambiente. Essa solução foi mantida em repouso por sete dias e, após esse período, procedeu-se a lavagem da quitosana com água até atingir-se $\mathrm{pH}$ neutro e a secagem em estufa a vácuo a $40{ }^{\circ} \mathrm{C}$ por 24 horas. A solução de cobertura e o filme de quitosana foram preparados com base em solução de $2 \%$ dessa quitosana desacetilada, ajustando-se o $\mathrm{pH}$ em 4,5 com ácido clorídrico concentrado. A seguir, a solução foi centrifugada por 15 minutos a $4.000 \mathrm{rpm}$. Ao sobrenadante obtido (solução filmogênica) foi adicionado 0,25 g de glicerol (Merck, Darmstadt), com agitação moderada e sob aquecimento (cerca de $50^{\circ} \mathrm{C}$ ).

A solução de cobertura e o filme de gelatina foram preparados hidratando-se, $10 \mathrm{~g}$ de gelatina (tipo A, 244 bloom, Leiner Davis, Brasil) por 1 hora em 100 $\mathrm{mL}$ de água destilada, e em seguida, aquecendo-se essa solução a $70{ }^{\circ} \mathrm{C}$ por 10 minutos e acrescentandose $0,5 \mathrm{~g}$ de glicerol.

As sementes de salsa 'Lisa comum' e brócolos 'Ramoso' (IAC), sem defensivos, foram recobertas com as coberturas de quitosana e gelatina em drageadeirapiloto, do tipo "pan coating", marca Incal, modelo JAA $110 \mathrm{E}$, de capacidade de $5 \mathrm{~L}$ e a uma velocidade de rotação de $25 \mathrm{rpm}$, no ITAL (Instituto de Tecnologia de Alimentos), normalmente usada na cobertura de confeitos de chocolate, balas e doces em geral. Para cada $100 \mathrm{~g}$ de sementes, utilizaram-se $10 \mathrm{~g}$ de solução de cobertura. As sementes foram colocadas na drageadeira e a solução de cobertura foi aspergida sobre elas, sendo mantidas em movimento durante a aplicação. Houve passagem de ar frio para a secagem da primeira camada de cobertura até que a aglomeração entre as sementes fosse reduzida. Em seguida, a solução de cobertura foi novamente aspergida e as sementes secas para a formação da segunda camada de cobertura, e assim sucessivamente. 
A fita de filme contendo as sementes foi preparada à base da solução filmogênica, colocada sobre placas de acrílico $(15 \times 15 \mathrm{~cm})$, com 25 sementes em espaçamento de $1 \mathrm{~cm}$ sobre a solução; posteriormente, nova aplicação da solução filmogênica, recobrindo-as. O volume da solução filmogênica colocada sobre a placa foi variado a fim de se obter diversas espessuras para as fitas contendo as sementes. Foram realizadas quatro repetições para cada tratamento.

As sementes, recobertas ou as incluídas nas fitas de filmes, foram colocadas sobre folha de papel de filtro totalmente umedecida com água destilada, em caixas de germinação (Gerbox). As caixas foram mantidas em germinadores a $20{ }^{\circ} \mathrm{C}$, por tempo dependente da espécie de semente, observando-se sua germinação. Foram realizadas quatro repetições de 25 sementes para cada tratamento.

$\mathrm{O}$ teste de vigor, por meio da emergência de plântulas, foi efetuado em casa de vegetação, do Centro de Horticultura do Instituto Agronômico (IAC), em Campinas, entre maio e setembro de 2003. Cada parcela correspondeu a um vaso de alumínio, com 18 $\mathrm{cm}$ de diâmetro e $15 \mathrm{~cm}$ de altura, onde foram semeadas 18 sementes. Cerca de quatro dias antes da semeadura, os vasos foram lavados com solução de Super Cândida (hipoclorito de sódio, hidróxido de sódio, cloreto de sódio e água) contendo de $2 \%$ a 2,5\% de cloro ativo $\mathrm{p} / \mathrm{p}$. No dia anterior à semeadura, os vasos foram preenchidos com terra de local não cultivado, peneirada, sendo tratada com solução de Mancozeb (Dithane) (20 g do produto por $10 \mathrm{~L}$ de água). As sementes foram colocadas na superfície do vaso, e cobertas com cerca de $60 \mathrm{~cm}^{3}$ de terra peneirada. A umidade do solo foi mantida próxima da saturação, colocando-se os vasos em caixas plásticas e mantendo-se a quantidade de água em nível constante (cerca de 1 L por caixa). Foram realizados dois experimentos.

Experimento 1: Constou dos seguintes tratamentos com sementes de brócolos: a) controle (sementes sem recobrimento); b) fita de filme de gelatina (sem sementes); c) fita de filme de quitosana (sem sementes); d) fita de filme de gelatina (com sementes); e) fita de filme de quitosana (com sementes); f) sementes com cobertura de quitosana (5 camadas); g) sementes com cobertura de quitosana (15 camadas); h) sementes com cobertura de gelatina (5 camadas). Utilizou-se o delineamento inteiramente casualizado, com três repetições. A contagem de plântulas emergidas foi realizada de três em três dias até o $30 .^{\circ}$ dia de semeadura. Foram utilizadas fitas de filmes sem inclusão de sementes para observar o tempo necessário para sua dissolução no solo.

Experimento 2: Constou dos seguintes tratamentos com sementes de salsa: a) sementes com cobertura de quitosana (5 camadas); b) sementes com cobertura de gelatina (5 camadas) e c) controle (sementes sem recobrimento). Foi utilizado o delineamento inteiramente casualizado, com sete repetições A contagem de plântulas emergidas foi efetuada de três em três dias, até o $30 .^{\circ}$ dia da semeadura.

Além de testes de emergência das plântulas, realizaram-se, também, nos dois experimentos, as determinações discriminadas a seguir:

a) Matéria fresca da parte aérea: aos 30 dias após a semeadura. Em cada parcela experimental, as plantas foram cortadas rente ao solo e pesadas em balança semi-analítica. Para a determinação da matéria fresca por planta, dividiu-se o valor obtido pelo número de plantas emergidas por parcela.

b) Matéria seca da parte aérea: após a determinação da matéria fresca, as plantas de cada parcela foram secas em estufa com circulação forçada de ar, a $65{ }^{\circ} \mathrm{C}$ por 24 horas. A seguir, foram pesadas em balança analítica. Para a determinação da matéria seca por planta, dividiu-se o valor obtido pelo número de plantas emergidas por parcela.

Os resultados foram submetidos à análise de variância (ANOVA) e as médias comparadas pelo teste de Tukey (5\% P), utilizando-se o programa SANEST (Sistema de Análise Estatística), de Zonta e MACHADO (1984).

\section{RESULTADOS E DISCUSSÕES}

\subsection{Efeito do número de camadas das coberturas e da espessura das fitas filmogênicas na germinação das sementes}

Na preparação das fitas filmogênicas, os filmes de quitosana mostraram-se frágeis e quebradiços, impedindo, assim, a variação da espessura da fita de filme (volume de solução filmogênica colocada na placa). Para os filmes de gelatina, cuja concentração utilizada foi de $10 \%$, foi possível variar-se a espessura das fitas.

No recobrimento das sementes em drageadeira, devido à viscosidade da solução filmogênica de gelatina, somente foi possível trabalhar com a aplicação de cinco camadas de cobertura das sementes. 
Experimentos preliminares definiram a utilização da cobertura de gelatina com aplicação de cinco camadas sobre as sementes de brócolos e a elaboração das fitas de filme de gelatina com várias espessuras (variação do volume de solução filmogênica colocada em cada placa: 8, 10, 12 e 15 $\mathrm{mL} /$ placa) para as sementes de salsa. Para a quitosana, foi possível variar a quantidade de camadas de cobertura (5, 10 e 15 camadas) para o recobrimento das sementes de brócolos, porém, somente foi viável o volume de $50 \mathrm{~mL} /$ placa de solução filmogênica para a fita contendo as sementes de salsa, devido à impossibilidade de manuseio da fita de filme de quitosana.

Pela análise da tabela 1, verifica-se que a germinação das sementes de brócolos não foi afetada pelas coberturas; conforme os resultados da tabela 2, observa-se que a germinação de sementes de salsa foi afetada pela sua incrustação em fitas biodegradáveis. Os valores obtidos indicaram a inviabilidade de utilização das fitas de filme de gelatina e de quitosana como transportadoras de sementes de salsa, nas condições estudadas.

Sementes recobertas, incluindo as peletizadas, têm sido usadas para muitas finalidades; uma delas é o melhor estabelecimento de plântulas, favorecendo a absorção de água livre pelas sementes no período de germinação. Nesse contexto, DADLANI et al. (1992) estudaram o potencial hidrófilo do polissacarídio alginato de sódio, combinando-o ao óxido de cálcio $(\mathrm{CaO})$ ou ao polietileno glicol (PEG) 8000 no recobrimento de sementes de arroz (Oryza sativa L.). Quando utilizaram 20\% (PEG) 8000 na solução, verificaram que a germinação foi prejudicada em situação de estresse de água. A adição de $\mathrm{CaO}$ na solução de recobrimento possibilitou o crescimento de plântula mais vigorosa, comparado ao crescimento de plântula de semente não-recoberta, resultado obtido pela melhor absorção de água da camada de recobrimento.

Em outro trabalho, foram realizados estudos para traçar a influência dos fertilizantes DAP, sulfato de zinco e borax adicionados aos pellets, na qualidade inicial da semente, na emergência, no potencial em campo e no armazenamento (por mais de três meses) de sementes de soja (SRIMATHI et al., 2002). Peletizandose as sementes com a adição de sulfato de zinco ( 250 $\mathrm{mg} \mathrm{kg}^{-1}$ de semente) houve melhora na sua qualidade inicial e no potencial de produção. $\mathrm{O}$ desempenho das sementes peletizadas, com e sem nutrientes, foi melhor do que no controle. O poder de germinação das sementes foi mantido por mais de 3 meses sem redução significativa na qualidade inicial.

Tabela 1. Porcentagem de sementes de brócolos com coberturas, germinadas em Gerbox a $20{ }^{\circ} \mathrm{C}$. UNICAMP, Campinas (SP)

\begin{tabular}{|c|c|c|}
\hline Tipo de cobertura & Número de camadas na cobertura & Germinação ${ }^{(1)}$ \\
\hline & & $\%$ \\
\hline Controle (sem cobertura) & - & $88 \mathrm{ab}$ \\
\hline \multirow[t]{3}{*}{ Cobertura de quitosana } & 5 & $96 a$ \\
\hline & 10 & $78 \mathrm{ab}$ \\
\hline & 15 & $72 b$ \\
\hline Cobertura de gelatina & 5 & $87 \mathrm{ab}$ \\
\hline D.M.S. $(5 \%$ P) & - & 20 \\
\hline C.V. (\%) & - & 5,8 \\
\hline
\end{tabular}

Médias na mesma linha com letras diferentes diferem entre si (Tukey, $\mathrm{P}<0,05)$.

$\left.{ }^{1}\right)$ Média de 4 triplicatas.

Tabela 2. Porcentagem de sementes de salsa encrustadas em fitas biodegradáveis, germinadas em Gerbox, a 20 'C. UNICAMP, Campinas (SP)

\begin{tabular}{lcc}
\hline Tipo de fita & Volume de solução filmogênica & Germinação $\left({ }^{1}\right)$ \\
\hline Controle & $\mathrm{mL} /$ placa & $\%$ \\
\hline Quitosana & - & $51,0 \mathrm{a}$ \\
\hline & 8 & $65,5 \mathrm{~b}$ \\
Gelatina & 10 & $24,0 \mathrm{c}$ \\
& 12 & $20,5 \mathrm{~cd}$ \\
$18,5 \mathrm{~d}$ & $15,5 \mathrm{~d}$ \\
\hline D.M.S. $(5 \%$ P) & 15 & 5,1 \\
C.V. $(\%)$ & - & 3,3 \\
\hline
\end{tabular}

Médias na mesma linha com letras diferentes diferem entre si (Tukey, $\mathrm{P}<0,05)$.

(1) Média de 4 triplicatas. 


\subsection{Germinação e vigor das sementes de brócolos inseridas em fitas}

A fita de filme de quitosana dissolveu-se completamente no solo em uma semana, enquanto a fita de filme de gelatina dissolveu-se em 15 dias, indicando maior solubilidade do filme de quitosana. Essa observação explica o valor mais baixo de germinação das sementes de brócolos nas fitas de gelatina, devido ao maior tempo para a sua dissolução no solo.

Na tabela 3, nas sementes incrustadas nas fitas de filme, observou-se comportamento inferior ao controle, com exceção da matéria fresca e seca por planta. O desempenho da fita de gelatina também foi inferior à fita de quitosana com relação à germinação e emergência de plântulas.

Outra análise realizada foi a comparação visual dos tamanhos das plantas em relação ao controle, sendo menores e também crescimento irregular, quando se utilizou a fita de gelatina .

Independentemente da forma como a germinação foi observada (Gerbox ou em solo), nas fitas de gelatina notaram-se valores muito baixos e diferentes das sementes, incluídas em fitas de quitosana (Tabela 3), possivelmente, devido ao maior tempo ocorrido para sua dissolução, retardando assim a germinação das sementes.

Considerando os resultados (Tabela 3), verificou-se a ineficiência das fitas de filme tanto de gelatina quanto de quitosana por comprometer a germinação e vigor das sementes de brócolos, quando comparados aos obtidos para as sementes controle.

Uma pesquisa foi desenvolvida para se estudar o impacto do filme polimérico na germinação de sementes de beterraba (DUAN e BURRIS, 1997). Entretanto, após a cobertura com o filme, a porcentagem de germinação variou de $68 \%$ a $94 \%$ e em metade dos lotes de sementes ocorreu redução significativa de germinação. Depois da remoção do pericarpo, não houve redução na germinação, indicando ou seja, a interação entre o filme e o pericarpo foi relevante na redução da germinação de sementes cobertas com filme.

Outro trabalho investigou a aplicação do inseticida, clorpirifos, sob a forma de cobertura de filme em sementes de repolho (Jуоті et al., 2003). Os tratamentos com as sementes cobertas com clorpirifos não afetaram adversamente a germinação em testes de laboratório e ainda proveram proteção contra os insetos que atacam o repolho, por algumas semanas após o transplante para o solo. Esse resultado está de acordo com estudos europeus anteriores, sobre o potencial da cobertura de filme com clorpirifos em sementes de repolho.

Em outra pesquisa, ensaios de germinação foram feitos com sementes de cenoura cobertas com filmes contendo inseticidas e os resultados comparados com a aplicação convencional de inseticidas por pulverização (NEUvel e Éster, 1990).

Os resultados expressam vantagens no uso de filmes para proteção das sementes ao ataque de insetos e para prevenção de perdas devido à aplicação de fungicidas e inseticidas durante o transporte. Os filmes também mostraram bons resultados na germinação em solos. $\mathrm{O}$ uso de filmes previne a difusão de açúcares e desenvolve um ambiente nos arredores das sementes contra microrganismos indesejáveis.

Há empresas do exterior usando fitas de papel com adesivo, ambos biodegradáveis, para sementes. Por exemplo, a empresa Gurney's Seed \& Nursery, oferece fitas de papel com sementes de diversas espécies, como cenoura, pimentão, pimenta, espinafre, alface, nabo e rabanete. Há garantia de espaçamento perfeito, sem falhas e necessidade de desbaste.

A empresa Park's Garden possui sementes de cenoura, alface, ervas aromáticas, flores de corte, girassol e zinia entre outras, em fitas de papel biodegradável. Assim, em alguns países do exterior as fitas de papel com sementes já estão disponíveis no comércio, para uso em jardins e hortas domésticas.

\subsection{Vigor de sementes de brócolos revestidas}

O revestimento de sementes de brócolos com quitosana (5 e 15 camadas) e gelatina (5 camadas) não afetou o vigor, como pode ser observado na tabela 4, constituindo-se em uma técnica potencial de uso no agronegócio. Em outros experimentos da literatura, quando foram aplicadas coberturas em sementes de algodão e soja, ocorreu aumento de $20 \%$ a $30 \%$ no índice de germinação, observando-se que quanto pior as condições para o crescimento das plantas, maiores foram as vantagens do revestimento das sementes (MARK et al., 1985). Em estudo realizado por SAUvE e SHIEL (1980), utilizando polímero em base líquida em combinação com ingredientes ativos, verificou-se que as sementes tratadas com substâncias adesivas melhoraram a emergência no solo. Todavia, problemas com a fitotoxicidade em sementes recobertas são ainda comuns, principalmente quando novos materiais poliméricos são aplicados, sem estudos de adequabilidade. 
Tabela 3. Germinação e vigor de sementes de brócolos encrustadas em fitas biodegradáveis. UNICAMP, Campinas (SP)

\begin{tabular}{lccccc}
\hline Caracteres avaliados & Controle $^{(1)}$ & Fita de gelatina $^{(1)}$ & Fita de Quitosana $^{(1)}$ & D.M.S. (5\%P) & C.V. \% \\
\hline Emergência das plantas (\%) & $94,0 \mathrm{a}$ & $18,5 \mathrm{c}$ & $51,9 \mathrm{~b}$ & 11,6 & 31,5 \\
Germinação em Gerbox (\%) & $95,0 \mathrm{a}$ & $14,0 \mathrm{c}$ & $67,0 \mathrm{~b}$ & 13,0 & 28,6 \\
Germinação total (dias) & $6 \mathrm{c}$ & $21 \mathrm{a}$ & $12 \mathrm{~b}$ & 5 & 30,4 \\
N. ${ }^{0}$ de plantas / parcela & $17,0 \mathrm{a}$ & $3,3 \mathrm{~b}$ & $9,3 \mathrm{~b}$ & 9,6 & 38,6 \\
Matéria seca (g)/parcela & $0,59 \mathrm{a}$ & $0,10 \mathrm{~b}$ & $0,18 \mathrm{~b}$ & 0,24 & 33,5 \\
Matéria fresca (g)/parcela & $4,79 \mathrm{a}$ & $1,20 \mathrm{~b}$ & $1,96 \mathrm{~b}$ & 2,73 & 41,1 \\
Matéria seca (g)/planta & $0,037 \mathrm{a}$ & $0,021 \mathrm{a}$ & $0,026 \mathrm{a}$ & 0,029 & 41,3 \\
Matéria fresca (g)/planta & $0,283 \mathrm{a}$ & $0,277 \mathrm{a}$ & $0,218 \mathrm{a}$ & 0,281 & 43,3 \\
\hline
\end{tabular}

Médias na mesma linha com letras diferentes diferem entre si (Tukey, $\mathrm{P}<0,05)$.

$\left({ }^{1}\right)$ Média de triplicatas.

Tabela 4. Resultados do teste de vigor em sementes de brócolos e salsa revestidas com coberturas de quitosana ou gelatina. UNICAMP, Campinas (SP)

\begin{tabular}{|c|c|c|c|c|c|}
\hline Tipo de cobertura & $\begin{array}{c}\text { N. }{ }^{\circ} \text { de plantas / } \\
\text { parcela }(1,2)\end{array}$ & $\begin{array}{c}\text { Matéria seca/ } \\
\text { parcela }\end{array}$ & $\begin{array}{c}\text { Matéria fresca/ } \\
\text { parcela }(1,2)\end{array}$ & $\begin{array}{c}\text { Matéria seca/ } \\
\text { planta }(1,2)\end{array}$ & $\begin{array}{c}\text { Matéria fresca / } \\
\text { planta }\end{array}$ \\
\hline & & 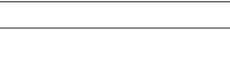 & $\mathrm{g}$ & +2 & \\
\hline & \multicolumn{5}{|c|}{ Brócolos com coberturas de gelatina e quitosana } \\
\hline Controle & $17,0 \mathrm{a}$ & $0,59 a$ & $4,79 \mathrm{a}$ & $0,0367 a$ & $0,2830 \mathrm{a}$ \\
\hline \multicolumn{6}{|l|}{ Quitosana } \\
\hline 5 camadas & $18,0 \mathrm{a}$ & $0,85 \mathrm{a}$ & $7,32 \mathrm{a}$ & $0,0470 \mathrm{a}$ & $0,4033 a$ \\
\hline \multicolumn{6}{|l|}{ Quitosana } \\
\hline 15 camadas & $17,3 a$ & $0,67 \mathrm{a}$ & $5,56 \mathrm{a}$ & $0,0387 a$ & $0,3220 \mathrm{a}$ \\
\hline \multicolumn{6}{|l|}{ Gelatina } \\
\hline 5 camadas & $19,0 \mathrm{a}$ & $0,52 \mathrm{a}$ & $4,33 \mathrm{a}$ & $0,0280 \mathrm{a}$ & $0,2327 a$ \\
\hline D.M.S. $(5 \% \mathrm{P})$ & 5,3 & 0,55 & 5,28 & 0,0307 & 0,2927 \\
\hline \multirow[t]{2}{*}{ C.V. $(\%)$} & 11,3 & 31,9 & 36,7 & 31,2 & 36,1 \\
\hline & \multicolumn{5}{|c|}{ Salsa com coberturas de gelatina e quitosana } \\
\hline Controle & $15,7 \mathrm{a}$ & $0,14 \mathrm{a}$ & $0,86 a$ & $0,0091 \mathrm{a}$ & 0,0543 a \\
\hline Gelatina & $17,9 \mathrm{a}$ & $0,15 \mathrm{a}$ & $0,88 \mathrm{a}$ & $0,0082 \mathrm{a}$ & $0,0500 \mathrm{a}$ \\
\hline Quitosana & $16,7 \mathrm{a}$ & $0,16 a$ & $0,95 \mathrm{a}$ & $0,0096 a$ & $0,0586 a$ \\
\hline D.M.S. $(5 \% \mathrm{P})$ & 3,0 & 0,05 & 0,33 & 0,0031 & 0,0205 \\
\hline C.V. (\%) & 13,3 & 24,9 & 26,6 & 25,2 & 27,7 \\
\hline
\end{tabular}

$\left({ }^{1}\right)$ Média de 4 replicatas. $\left({ }^{2}\right)$ Médias na mesma coluna com letras diferentes diferem entre si (Tukey, P<0,05). 


\subsection{Vigor de sementes de salsa revestidas}

Pela avaliação dos resultados da Tabela 4, constatou-se que não houve diferença entre os tratamentos para todos os testes de vigor realizados. Desse modo, pode-se dizer que a cobertura de sementes em drageadeira também não afetou o vigor de sementes de salsa, apresentando potencial de uso como cobertura protetora das sementes. WEST et al. (1985), verificaram que a aplicação da cobertura à base de cloreto de polivinilideno (PVDC), em sementes de soja, promoveu uma germinação mais rápida do que nas sementes sem a cobertura.

\section{CONCLUSÕES}

1. A inclusão de sementes em fitas de gelatina e quitosana afetou negativamente a germinação da salsa e brócolos e o vigor do brócolos.

2. O recobrimento de sementes com coberturas de quitosana ou gelatina não afetou sua qualidade, em termos de capacidade de germinação e de vigor em semente de brócolos e o vigor em sementes de salsa.

3. A utilização do recobrimento de sementes, funcionando como veículo para substâncias que melhorem as características de germinação e o crescimento das sementes estudadas, é viável.

\section{AGRADECIMENTOS}

À FAPESP (Fundação de Amparo à Pesquisa do Estado de São Paulo) pela bolsa de iniciação científica concedida à autora Paula S. P. Proença, ao IAC (Instituto Agronômico), pelo fornecimento das sementes e pelo auxílio nos testes de germinação em solo, a Marise B. Queiroz, pelo uso da drageadeira no ITAL (Instituto de Tecnologia de Alimentos) e ao Senhor Antônio Francisco de Oliveira, pelas idéias e sugestões a esse trabalho e em testes preliminares .

\section{REFERÊNCIAS}

AMARANTE C.; BANKS N. H.. Postharvest physiology and quality of coated fruits and vegetables. Horticultural Reviews, Londres, v.26, p.161-238, 2001.

BUTLER, R. Coatings, films \& treatments. Seed World, Des Plaines, v.10, p.18-24, 1993.

DADLANI, M.; SHENOY, V.V.; SESHU, D.V. Seed coating to improve stand establishment in rice. Seed Science \& Technology, v.20, p.307-313, 1992.
DANDURAND, L.M.; KNUDSEN, G.R. Influence of Pseudomonas fluorescens on hyphal growth and biocontrol activity of Trichoderma harzianum in the spermosphere of pea. Phytopathology, St Paul, v.83, n.3, p. 265-270, 1993.

DUAN, X.; BURRIS, J.S. Seed physiology, production \& technology: film coating impairs leaching of germination inhibitors in sugar beet seed. Crop Science, Madison, v.37, n.2, p.515-520, 1997.

GURNEY'S SEED \& NURSERY. Disponível em < gurneys.com>. Acesso em 1. ${ }^{\circ}$ dez. 2004.

JYOTI, J.L.; SHELTON, A.M.; TAYLOR, A.G. Journal of Entomological Science, New York, v.38, n.4, p.553-565, 2003.

MARK, H.F.; BIKALES, N.M.; OVERBERGER, C.G. Encyclopedia of Polymer Science and Engineering. New York: Wiley Interscience, 1985. p. 611-621.

NEUVEL, J., ESTER, A. Protecting carrots against carrot root fly larvae by filmcoating the seds with inseticids. Research Station for Arable Farming and Field Prodution of Vegetables, v. 20, p.49-56, 1990.

NUSSINOVITCH, A. Hydrocolloid Application: Gum Technology in the food and other industries. Londres: Blackie Academic \& Professional, 1997. p.168-189.

PARK, H. J. Development of advanced edible coatings for fruits. Trends in Food Science and Technology, Oxford, v.10, n. 8, p.254-260, 1999.

PARK'S GARDEN. Disponível em www.parkseed.com. Acesso em $1 .^{\circ}$ dez. 2004.

SHAYA, E.; RAVID, U.; PASTER, N.; JUVEN, B.; ZISMAN, U.; PISSAREV, V. Fumigant toxicity of essential oils against four major stored-products insects. Journal of Chemical Ecology, New York, v.17, n.3, p.499-504, 1991.

SAUVE, E.M.; SHIEL, R.S. Coating seeds with polyvinyl resins turnip, carrot and cabbage seeds, fungicide application. Journal of Horticultural Science, v.55, n.4, p. p.371-373, 1980.

SRIMATHI, P.; MALARKODI, K.; GEETHA, R.; KRISHNASAMY, V. Nutrient pelleting to augument quality seed production in soybean. Seed Research, New Delhi, v.30, n.2, p.186-189, 2002.

TANADA-PALMU, P.S.; GROSSO, C.R.F. Edible wheat gluten films: development, mechanical and barrier properties and application to strawberries (Fragaria Ananassa). Boletim do CEPPA, Curitiba, v.20, n.2, p.291-308, 2002a.

TANADA-PALMU, P.S.; GROSSO, C.R.F. Wheat gluten composite and bilayer edible films: effect of lipid addition. Research Advances in Agricultural \& Food Chemistry, Kerala, v.3, p.53-60, 2002b.

WEST, S.H.; LOFTIN, S.K.; WAHL, M.; BATICH, C.D.; BEATTY, C.L. Polymers as moisture barriers to maintain seed quality. Crop Science, Madison, v.25, p.941-944, 1985.

ZONTA, E.P.; MACHADO, A.A. SANEST: Sistema de análise estatística para microcomputadores (software). Pelotas: UFPEL, 1984. 